\title{
Stability Studies of Microencapsulated Anthocyanins of Roselle (Hibiscus Sabdariffa L) In Native Starch and Its Potential Application in Jam Production
}

\author{
Gibson Lucky Arueya ${ }^{1}$,BamideleOlumide Akomolafe ${ }^{2}$ \\ ${ }^{1,2}$ Department of Food technology, University of Ibadan, Ibadan, Nigeria
}

\begin{abstract}
The significance of natural food colorants such as Roselle anthocyanins had been known for decades. However their stability in and out of food systems is still a challenge. This work was aimed at mitigating this phenomenon.

Various solvent extracted, microencapsulated in native corn starch and freeze dried samples[ethanol acidified with 1\% citric acid (FDMEE), 2\% citric acid solution (FDMCE) as well as distilled water (FDMWE) ] were prepared using standard techniques. These were kept under room temperature conditions for eight weeks and physicochemical evaluations conducted periodically. Some of these were utilized (1\% inclusion) in the production of jam and evaluated by a 30 man sensory panel.

Colour intensity indicated by Chroma Values $\left(a^{*}\right)$ of microencapsulated samples were: FDMEE (2.20 $\pm 0.01), F D M C E(3.05 \pm 0.02)$ and FDMWE (1.98 \pm 0.00$)$. Analysis of total soluble solids ( ${ }^{0}$ Brix), titratable acidity (\% citric acid) and anthocyanins $(\mathrm{mg} / 100 \mathrm{~g})$ in this order gave the following FDMEE $(5.1 \pm 0.00$,

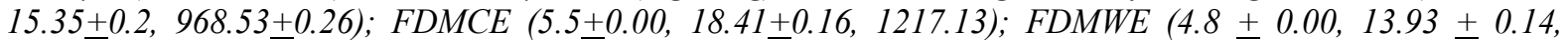
$882.5 \overline{1} \pm 0.44)$. These values were significantly different from their non-encapsulated equivalents $(\bar{p}<0.05)$. Sensory scores for jam containing microencapsulated extract compared favourably with the non-encapsulated inclusive samples.
\end{abstract}

Freeze dried microencapsulated anthocyanins in native corn starch is colour stable and valuable in the production of acceptable jam.

Keywords:Roselle, Anthocyanins, colour-extract, microcapsulation, freeze drying

\section{Introduction}

There has been much interest in the development of natural food colorants following growing safety concerns over continued use of synthetic or artificial colours in foods. Roselle (Hibiscus Sabdariffa L.) pigments, representing a potent source of anthoyanins holds promise as a large commercial potential source of natural food colourants (red-violent) (Hendry and Houghton, 1996).

Anthocyanins are little used in foods and beverage, since they show low stability under processing and storage conditions when compared to artificial dyes. Bridle and Timberlake (1997) reported that in acidic media, heating process caused four anthocyanin structures to shift towards the colourless carbinol base and chalcone forms which became paler in colour. In addition, other phenolic compounds found in Roselle extract such as catechin also react with anthocyanins resulting in complex formation leading to colour changes (Tsai and Huang, 2004). The degradation effect of oxygen on Anthocyanin results in brown product concentration (Stanciu et al., 2010). Anthocyanins are highly unstable molecules in food matrix. The colour stability of Anthocyanins is strongly affected by $\mathrm{pH}$, solvents, temperature, anthocyanin concentration and structure, oxygen, light, enzymes, and other accompanying substances (Rein, 2005, Chumsri etal., 2008).

To mitigate these challenges in various food systems Esselen and Sammy $(1973,1975)$ evaluated the magnitude of various factors influencing the stability of anthocyanin extract from H. Sabdariffa. Clydesdale et.al (1979) studied closely the stability of spray dried Roselle anthocyanin in dry food formulations. The likely effects of the addition of butylated hydroxyl anisole (BHA) and related compounds on the stability of anthocyanin was explored by Pouget et al. (1990). Gradinaru etal 2003 studied the stability of freeze dried anthocyanin from H. Sabdariffa encapsulated with pullulan and kept under different water activities and temperatures. Although improved stability was recorded, pullulan (an extra cellular polysaccharide excreted by the fungus Aureobasidiumpullulan) is slowly digested in humans resulting in symptoms of gastrointestinal intolerance (Wolf et al 2003). The stability of freeze dried Roselle anthocyanins microencapsulated separately in dried maltodextrin D.E 10,maltodextrinD.E 20 and gum arabic was evaluated by Selim et al. (2008). They found maltodextrin D.E 20 to be most effective under all storage conditions and in food products. However, the safety and health implications of the use of maltodextrins as an artificial food additive continues to generate controversy. 
Owing to increasing health consciousness over the years regarding artificial food additives (Ghorpade et al., 1995), there is need to explore other encapsulating agents such as native starch for Roselle anthocyanins because of its availability and wide acceptability as food. Although its application in largely aqueous food system may be limited, the outcome in complex food formulations might be different. No report has been foundon freeze drying of Roselle pigment using native corn starch. It is therefore the objective of this work to extract Roselle pigments using different solvents, freeze dry,microcapsulate in native corn starch and store under tropical room temperature conditions while monitoring likely changes in physicochemical indices particularly colour intensity. The stability in a complex food systems such as jam stored under room temperature conditions together with its consumer acceptability or otherwise whencompared to jam containing the synthetic colour equivalent would also be explored.

\section{Materials and Methods}

Dried Roselle Calyces were obtained from Bodija market, Ibadan, Nigeria. They were washed in water to remove any adhering dirt and air dried under closed conditions. The calyces so dried were stored at $4^{0} \mathrm{C}$ till when it was put to use. Three solvents were used in the extraction of pigments from Roselle calyces. The solvents are: Ethanol acidified with 1\% citric acid, 2\% Citric acid solution and Distilled water. Native Corn Starch (food grade) produced by Hui Shi Biochemical Regent Co., Ltd. (Shanghai, China) was obtained and used as encapsulating agent for the pigment. The ethanol and citric acid reagents were all of analytical grade and purchased fromchemical suppliers.

\subsection{Extraction of Pigment}

Roselle pigments were extracted with solvent according to Mattuk (1998). The evaluated solvents were: Ethanol acidified with $1 \%$ citric acid, $2 \%$ citric acid solution and distilled water. Extraction of pigments was carried out according to the procedures described by Pougetet al. (1990). One hundred gram of ground dried calyces were thoroughly mixed with a suitable amount of solvent in $500 \mathrm{ml}$ flask and incubated overnight in a refrigerator at $4{ }^{\circ} \mathrm{C}$. The soluble extract was filtered usingWhatman No. 1 filter paper to obtain Roselle pigment extract. Following extraction, the pigments were subjected to vacuum concentration prior to drying. A BüchiRotavapor was used to concentrate the samples and to separate all the ethanol at $40{ }^{\circ} \mathrm{C}$.

\section{$2.2 \quad$ Freeze Drying}

Corn starch $15 \%(\mathrm{w} / \mathrm{v})$ was added to clarified concentrated Roselle extracts of specified volume (280 $\mathrm{ml}$ ) and made to pass through a $150 \mu \mathrm{m}$ mesh for $10 \mathrm{mins}$ and transferred into the Freeze dryer (Telstar cryodos, 2008 model, Spain) for $12 \mathrm{hrs}$.

\subsection{Physicochemical Analysis}

The physico-chemical analysis (excluding colour intensity and moisture content determinations) of the microencapsulated and nonencapsulated pigment were evaluated at intervals of four days for a period of 22 days to monitor possible changes in chemical properties.

\subsubsection{Colour Determination}

Colour determination was evaluated objectively using, a Chroma meter CR-41O, Japan. A known quantity of the sample was placed in the quartz cell. The colour characteristics including (i) lightness (L), (ii)redness/greenness $( \pm \mathrm{a})$, and (iii)blueness/yellowness $( \pm b)$ of the calyces weremeasured by reading the meter.The samples were analyzedin triplicate.

\subsubsection{Total Pigment Content}

Anthocyanins content of Roselle extract was determined colorimetrically according to the procedure described by Du and Francis (1973). A known volume of the filtered extract was diluted to $100 \mathrm{ml}$ with the extracting solvent. The colour intensity was measured at $520 \mathrm{~nm}$ for distilled water and $535 \mathrm{~nm}$ for acidified ethanol and methanol using Spectrophotometer. The total Anthocyanins content referred to as delphenidin-3,5sumboside was calculated using the following equation.

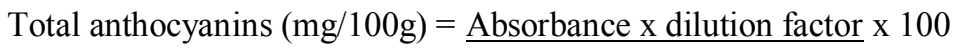

Sample weight x 55.9

\subsubsection{Determination of Moisture Content}

Empty dishes (made of porcelain) were dried using drying oven for $1 \mathrm{hr}$ at $100^{\circ} \mathrm{C}$. The dishes were cooled for $30 \mathrm{mins}$ in a desiccator (with granular silica gel) and weighed using a digital analytical balance to the nearest milligram. Three grams of well prepared samples (in triplicates) were weighed into the dry dishes. The 
dishes and their contents were placed in drying oven and dried for $5 \mathrm{hr}$ at $100^{\circ} \mathrm{C}$. These were next cooled in a desiccator to room temperature and weighed. The procedure was repeated until a constant weight was recorded (AOAC, 2000).

$$
\% \text { Moisture }=\frac{M_{\text {initial }}-M_{\text {dried }} x}{M_{\text {initial }}}
$$

$M_{\text {initial }}=$ mass of sample before drying

$\mathrm{M}_{\text {dried }}=$ mass of sample after drying

2.3.4 Determination of $\mathrm{pH}$

About $30 \mathrm{~g}$ of the juiceslurry was blended with $90 \mathrm{~mL}$ of distilled water and filtered to obtain a filterate. The $\mathrm{pH}$ electrode earlier rinsed in distilled water was placed in the filtrate and allowed to stabilize for few minutes and the $\mathrm{pH}$ value noted (AOAC, 2000).

\subsubsection{Determination of Titratable Acidity}

About $25 \mathrm{~mL}$ of filtrate was transferred into $125 \mathrm{~mL}$ conical flask. A $25 \mathrm{~mL}$ burette was filled with $0.1 \mathrm{NNaOH}$ and adjusted to zero. About two to three drops of phenolphthalein indicator was added to the conical flask containing the filtrate. The filtrate was titrated with $0.1 \mathrm{~N} \mathrm{NaOH}$ until indicator changed to pink and the volume was recorded. Titratable acidity was calculated as \% lactic acid (AOAC, 2000).

$\%$ Acidity $=$ A x N x 0.009

$\mathrm{A}=$ Average titre Value

$\mathrm{N}=$ Normality of $\mathrm{NaOH}[0.1]$

$0.009=$ Equivalent factor of citric acid

\subsubsection{The Total Soluble Solids (T.S.S)}

The total soluble solids (T.S.S) $\left({ }^{\circ} \mathrm{Brix}\right)$ of samples was determined according to $\mathrm{AOAC}(2000)$ at room temperature $\left(25^{\circ} \mathrm{C} \pm 1\right)$ expressed as ${ }^{\circ} \mathrm{Brix}(0-90)$, was determined with a hand Refractometer (ATAGO, Japan). The samples were analysed in triplicates.

\subsubsection{Determination of Ascorbic Acid}

Ascorbic acid (vitamin C) was determined according to the indophenols method (AOAC, 2000). One gram of the sample was weighed and $10 \mathrm{ml}$ of water was added. After filtration, $100 \mathrm{ml}$ of water was added. Phenolpthalein was used as indicator. The supernatant was titrated against $0.005 \mathrm{~mol} \mathrm{~L}^{-1}$ iodine solution until a dark blue black end point was reached. Ascorbic acid was calculated using stoichiometric method. Analysis was carried out at intervals of four days for 22days.

\subsubsection{Solubility Determination}

Solubility was measured according to the method of Anderson and Frances (2004). Two and half grammes of Roselle samples were dispensed into $25 \mathrm{ml}$ of distilled waterwhile taking care to break up any lumps using a glass rod. After 30 min of stirring, the dispersion was rinsed into tarred centrifuge tubes made up to $32.5 \mathrm{ml}$ and then centrifuged at $3000 \times \mathrm{g}$ for $10 \mathrm{~min}$. The supernatant was then decanted and the weight of its solid content determined after it had been evaporated to a constant weight. The Water Solubility Index (WSI) was then calculated as: WSI = wt of dissolved solids in supernatant/ Wt. of dry Roselle sample.

\subsection{Application of the Pigment Extract in the Production of Jam}

The Jam was prepared according to the method of Food and Agriculture Organization (FAO) (1997). Encapsulated and non-encapsulated Roselle extract powder with the highest colour intensity was added to Water melon Jam at 1\% concentrations of the Jam mixture; synthetic food colourant (Raspberry E124) was also added at $1 \%$ concentration to a separate Jam mix. Control sample of Water melon Jam (without addition of any food colourant) was prepared under the same conditions.

\subsection{Sensory Evaluation}

Water melon Fruit Jam for organoleptic evaluation were prepared aseptically in clean transparent sterilized closed containers and served fresh on the test day. After two months of storage (the optimum shelf life of homemade jams under tropical room temperature conditions), portions were also presented for evaluation. Thirty member panel were selected. The sensory characteristics scored were colour, mouthfeel, texture and overall acceptability of the samples using a 9-point hedonic scale ranging from dislike extremely (1) to like extremely (9). During product testing, panel members were allowed to rinse their mouth at intervals. 
2.6 Statistical Analysis

Data were analyzed for variance using SPSS No. 17.

\section{Results and Discussion}

3.1 Physicochemical properties of Freeze dried Roselle pigments

The outcome of various physicochemical evaluations on the Roselle samples are illustrated below beginning with colour determination (Table 1).

\subsubsection{Colour}

The citric acid extract presented a higher lightness value, indicating a more radiant brightly coloured extract in comparison with other extracting media. The colour characteristics $\mathrm{L}^{*}, \mathrm{a}^{*}$ and $\mathrm{b}^{*}$ mean values of dried Roselle powder were $14.14,2.88$ and -0.70 , respectively. The citric acid extracts exhibited a high value of a* (3.13-3.17) followed by ethanol extracts and distilled water extracts with $\mathrm{a}^{*}(3.01-3.13)$ and (2.06-2.08) respectively. The high value of $\mathrm{a}^{*}$ associated with some extracts showed that the inclusion of acid in the extracting media exerted a higher colour intensity. The relative lower values $\mathrm{a}^{*}$ of their encapsulated equivalentmay be attributable to the effect of added encapsulating agent prior to freeze drying (Abou-Arab et al., 2011).

\subsubsection{Solubility}

The solubility of Dried Roselle Powder (DRP) and Freeze Dried Extracts (FDE) pigment and powder used in preparing the micro emulsion systems are also evident (Table 1). Obviously from the data DRP has poor solubility in aqueous solution. The values presented ranged from 5.43\% (DRP) to $9.60 \%$ (FDMEE). There were significant differencesamong DRP, FDMEE and FDEE sample extractswith FDMEE and DRP having comparatively high and low solubility values respectively. The presence of fibre in the DRP sample and its absence in the others (which are essentially its direct extract) may account for the wide differences in the solubility values. The soluble starch fraction in the microencapsulated samples evidently may have enhanced their solubility. Microencapsulation had long been entitiesused as potential delivery system for hydrophilic agents due to their stability over time, capacity for high solubilisation and ease of application in food system (Parize et al., 2008).

\subsubsection{Moisture}

The moisture content of the Roselle samples ranged from $13.53 \%$ to $16.47 \%$ as presented (Table 1). The results of $13.53 \%$ for the air dried samples are in agreement with those reported by Adenipeku(1998). However, there is significant difference between samples of DRP and roselle extracts (FDCE, FDWE, FDMWE). The extracts wereindeed higher and may have being due to their intrinsic propensity for moisture retention and or uptake

\subsection{4 $\mathrm{pH}$}

The results of the $\mathrm{pH}$ evaluation (Table 1) showed that the $\mathrm{pH}$ of the citric acid extracts were low followed by the ethanol extracts while distilled water extracts were highest. This may be related to the inclusion of acid in the extracting medium (Abou-Arab et al., 2011). The $\mathrm{pH}$ of non-encapsulated pigments range was (2.62-2.86), while their microencapsulated counterparts was (2.62-2.85). Results obtained for the freeze dried water extracts and DRP differed significantly from those of other solvent extracts.

\subsubsection{Titratable acidity}

The total titratable acidity correlates with the $\mathrm{pH}$ of the extracts as shown(Table 1). The values obtained for non-encapsulated pigments range was (14.08-19.04\%), while microencapsulated pigments ranged between $13.93 \%$ and $18.41 \%$. The total titratable acidity of the microencapsulated extracts were significantly reduced due to the inclusion of the encapsulating agent. This may be due to the inherent low titratable acidity property of corn starch as reported by Sandhu and Singh (2007).

\subsubsection{Total soluble solids}

The total soluble solids as indicated in (Table 1) showed that citric acid extracts exhibited a high total soluble solids ostensibly because citric acid has a high pigment extraction potential followed by ethanol (AbouArab et al., 2011). The values obtained showed that DRP differed significantly from the other extracts in this respect. The observed differences in the total soluble solids of the roselle sample might be due to the presence of other phenolic compounds present in the extracts (Builders et al., 2010). 


\subsubsection{Ascorbic acid content}

The calyces (DRP) are rich in vitamin C (185.52mg/100g) (Table 1). A close examination indicates that the citric acid extract had a high ascorbic acid content followed by ethanol. There has been no other reported solvent type able to give maximum extraction yield of ascorbic acid (Selim et al., 2008). The ascorbic acid of the microencapsulated extracts decreased significantly perhaps as a result of the effect of encapsulating agent. The non-encapsulated pigments range was $(136.47-163.02 \mathrm{mg} / 100 \mathrm{~g})$, while the encapsulated pigments yielded between 131.08 and $154.03 \mathrm{mg} / 100 \mathrm{~g}$. The value of ascorbic acid obtained for the DRP is in agreement with those reported by Abou-Arab et al., (2011).

\subsubsection{Anthocyanin content}

The anthocyanin content evaluated for samples stored at $26 \pm 2^{\circ} \mathrm{C}$ in translucent high density polyethylene bag (HDPE) is shown (Table 1).It is evident that anthocyanins values for the non-encapsulated (or free) pigments, were higher than that for encapsulated pigments.(1262.76 mg/100g and $1217.13 \mathrm{mg} / 100 \mathrm{~g})$. Similar results have been reported by Flink (1985) who observed loss in freeze-dried elderberry anthocyaninsas significant only when $a_{w}$ values were above 0.51 . The explanation of these findings lies in the fact that the reaction of anthocyanins is controlled by the mobility of chemical reactants (Leung, 1987). At low $\mathrm{a}_{\mathrm{w}}$, water is tightly bound to the surface polar sites and is generally not available for any kind of reactions. Increasing the moisture content results in faster mobility of the reactants, which leads to a greater reaction rate. Increased anthocyanin concentration promotes higher colour stability (Giustic and Wrolstad, 2003).

Table 1: Some physicochemical properties of the sample extracts

\begin{tabular}{|c|c|c|c|c|c|c|c|}
\hline Properties & DRP & FDEE & FDCE & FDWE & FDMEE & FDMCE & FDMWE \\
\hline Colour & $14.14 \pm 0.05^{\mathrm{d}}$ & $14.35 \pm 0.08$ & $15.91 \pm 0.07$ & $13.94 \pm 0.02$ & $14.20 \pm 0.03$ & $16.36 \pm 0.02$ & $14.03 \pm 0.01$ \\
\hline $\mathrm{L}^{*}$ & $2.88 \pm 0.02^{\mathrm{c}}$ & & & & & & \\
\hline$a^{*}$ & $-0.7 \pm 0.07^{\mathrm{a}}$ & $3.07 \pm 0.06^{\mathrm{b}}$ & $3.15 \pm 0.02^{\mathrm{a}}$ & $2.07 \pm 0.01^{\mathrm{d}}$ & $2.02 \pm 0.01^{\mathrm{d}}$ & $3.05 \pm 0.02^{\mathrm{b}}$ & $1.98 \pm 0.00^{\mathrm{e}}$ \\
\hline$b^{*}$ & & - & $-0.87 \pm 0.04^{b}$ & - & & $-0.96 \pm 0.01^{\mathrm{c}}$ & $0.72 \pm 0.01^{\mathrm{a}}$ \\
\hline & & $1.08 \pm 0.04^{\mathrm{d}}$ & & $0.77 \pm 0.01^{\mathrm{a}}$ & & & \\
\hline $\begin{array}{l}\text { Solubility } \\
(\%)\end{array}$ & $5.43 \pm 0.05^{\mathrm{e}}$ & $7.34 \pm 0.04^{\mathrm{c}}$ & $6.15 \pm 0.08^{d}$ & $6.18 \pm 0.12^{\mathrm{d}}$ & $9.60 \pm 0.04^{\mathrm{a}}$ & $8.81 \pm 0.03^{b}$ & $8.65 \pm 0.09^{b}$ \\
\hline $\begin{array}{l}\text { Moisture } \\
\text { content }\end{array}$ & $13.53 \pm 0.02^{\mathrm{e}}$ & $\underset{f}{13.18 \pm 0.15}$ & $\underset{b}{15.82 \pm 0.13}$ & ${ }_{\mathrm{a}} 16.47 \pm 0.28$ & $13.17 \pm 0.23$ & $14.42 \pm 0.23$ & ${ }_{c}^{15.49 \pm 0.15}$ \\
\hline $\mathrm{pH}$ & $2.89 \pm 0.05^{\mathrm{a}}$ & $2.74 \pm 0.00^{\mathrm{b}}$ & $2.62 \pm 0.03^{\mathrm{d}}$ & $2.86 \pm 0.01^{\mathrm{a}}$ & $2.66 \pm 0.05^{\mathrm{c}}$ & $2.62 \pm 0.05^{\mathrm{d}}$ & $2.85 \pm 0.02^{\mathrm{a}}$ \\
\hline $\begin{array}{l}\text { Total } \\
\text { titratable } \\
\text { acidity }(\% \\
\text { citric acid })\end{array}$ & $15.76 \pm 0.12^{\mathrm{d}}$ & $16.77 \pm 0.4^{\mathrm{c}}$ & $\underset{\mathrm{a}}{19.04 \pm 0.16}$ & $14.08 \pm 0.1^{\mathrm{e}}$ & $15.37 \pm 0.2^{\mathrm{d}}$ & $\underset{b}{18.41 \pm 0.16}$ & ${ }_{f} 13.93 \pm 0.14$ \\
\hline $\begin{array}{l}\text { Total } \\
\text { soluble } \\
\text { solids } \\
\left({ }^{0} \text { Brix }\right)\end{array}$ & $4.5 \pm 0.00^{\mathrm{d}}$ & $5.1 \pm 0.00^{\mathrm{b}}$ & $5.5 \pm 0.00^{\mathrm{a}}$ & $4.8 \pm 0.00^{\mathrm{c}}$ & $5.1 \pm 0.00^{\mathrm{b}}$ & $5.5 \pm 0.00^{\mathrm{a}}$ & $4.8 \pm 0.00^{\mathrm{c}}$ \\
\hline Ascorbic & $185.52 \pm 3.4$ & $151.69 \pm 0.2$ & $163.02 \pm 0.5$ & $136.47 \pm 0.9$ & $143.78 \pm 0.3$ & $154.03 \pm 0.6$ & $131.08 \pm 0.2$ \\
\hline $\begin{array}{l}\text { acid } \\
(\mathrm{mg} / 100 \mathrm{~g})\end{array}$ & $7^{\mathrm{a}}$ & $9^{c}$ & $9^{b}$ & $2^{\mathrm{e}}$ & $5^{d}$ & $5^{c}$ & $9^{f}$ \\
\hline $\begin{array}{l}\text { Anthocyani } \\
\text { ns } \\
(\mathrm{mg} / 100 \mathrm{~g})\end{array}$ & $\begin{array}{l}2087.89 \pm 2 . \\
79^{\mathrm{a}}\end{array}$ & $\begin{array}{l}969.60 \pm 1.9 \\
4^{c}\end{array}$ & $\begin{array}{l}1262.76 \pm 1 \\
96^{b}\end{array}$ & $\begin{array}{l}887.43 \pm 1.2 \\
d\end{array}$ & $\begin{array}{l}968.53 \pm 1.1 \\
1^{c}\end{array}$ & $\begin{array}{l}1217.13 \pm 0 . \\
26^{b}\end{array}$ & $\begin{array}{l}882.51 \pm 0.4 \\
4^{\mathrm{d}}\end{array}$ \\
\hline
\end{tabular}

N.B:

DRP-Dried Roselle Powder, FDEE- Freeze dried ethanol extract, FDCE- Freeze dried citric acid extract, FDWE- Freeze dried water extract, FDMEE- Freeze dried microencapsulated ethanol extract, FDMCEFreeze dried microencapsulated citric acid extract, FDMWE- Freeze dried microencapsulated water extract. All values are means of triplicate determinations \pm standard deviation (SD) Means within rows with different letters are significantly different $(\mathrm{P}<0.05)$ 
3.2 Variation in colour intensity with storage duration

Changes in colour intensity during storage of the non-encapsulated roselle extracts is vividly portrayed in Fig. 1. The chroma $\left(a^{*}\right)$ values obtained varied in the period under study: FDEE (3.07-2.78); FDCE (3.153.01), and FDWE (2.07-1.95). Chroma ( $\left.\mathrm{a}^{*}\right)$ values of the non-encapsulated samples showed a significant decline from commencement of storage to the end of eight (8) weeks. The FDCE showed relative higher colour intensity than FDEE and FDWE evidently due to the medium of extraction. The chroma $\left(a^{*}\right)$ values exhibited significant variations during storage among the non-encapsulated extracts with FDEE samples being the least stable. The variation in colour intensity of the samples may be due to presence of other phenolic compounds and their inherent water activities $\left(\mathrm{a}_{\mathrm{w}}\right)$ (Abou-Arab et al., 2011).

The chroma $\left(\mathrm{a}^{*}\right)$ values for the microcapsulated extracts (Fig. 2) also varied: $\operatorname{FDMEE}(2.02-2.01)$, FDMCE (3.05 - 3.03)and FDMWE (1.98 - 1.97). Results obtained for the microencapsulated Roselle pigments though showed lower $\left(\mathrm{a}^{*}\right)$ valueswhen compared to their non-encapsulated counterparts. Comparatively they are more stable with storage time. This may be due to the protective barrier offered by the corn starch (Leahy et al., 1983).

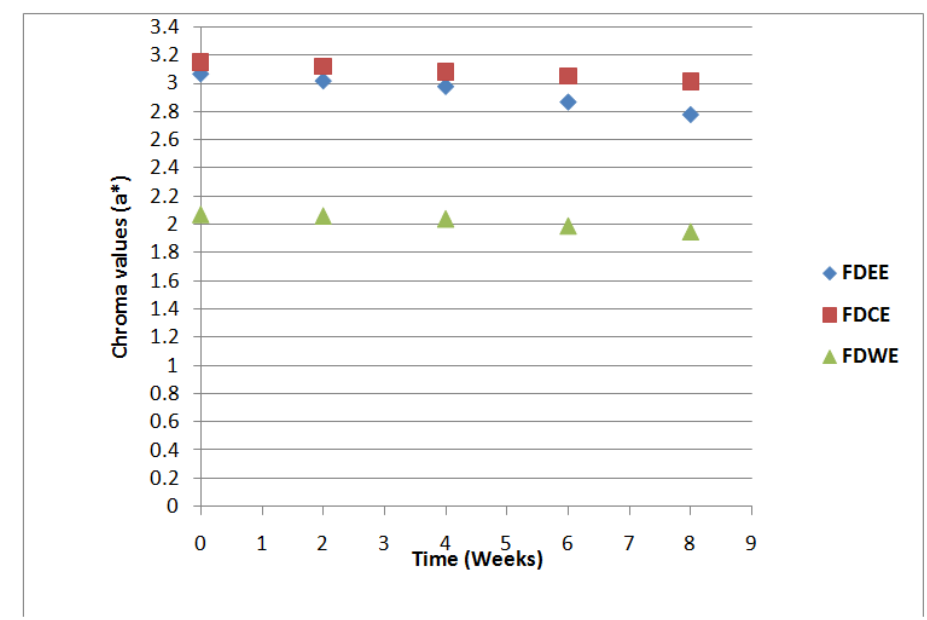

Figure 1: Changes in colour during storage of non-encapsulated extracts at $26^{0} \mathrm{C} \pm 2$

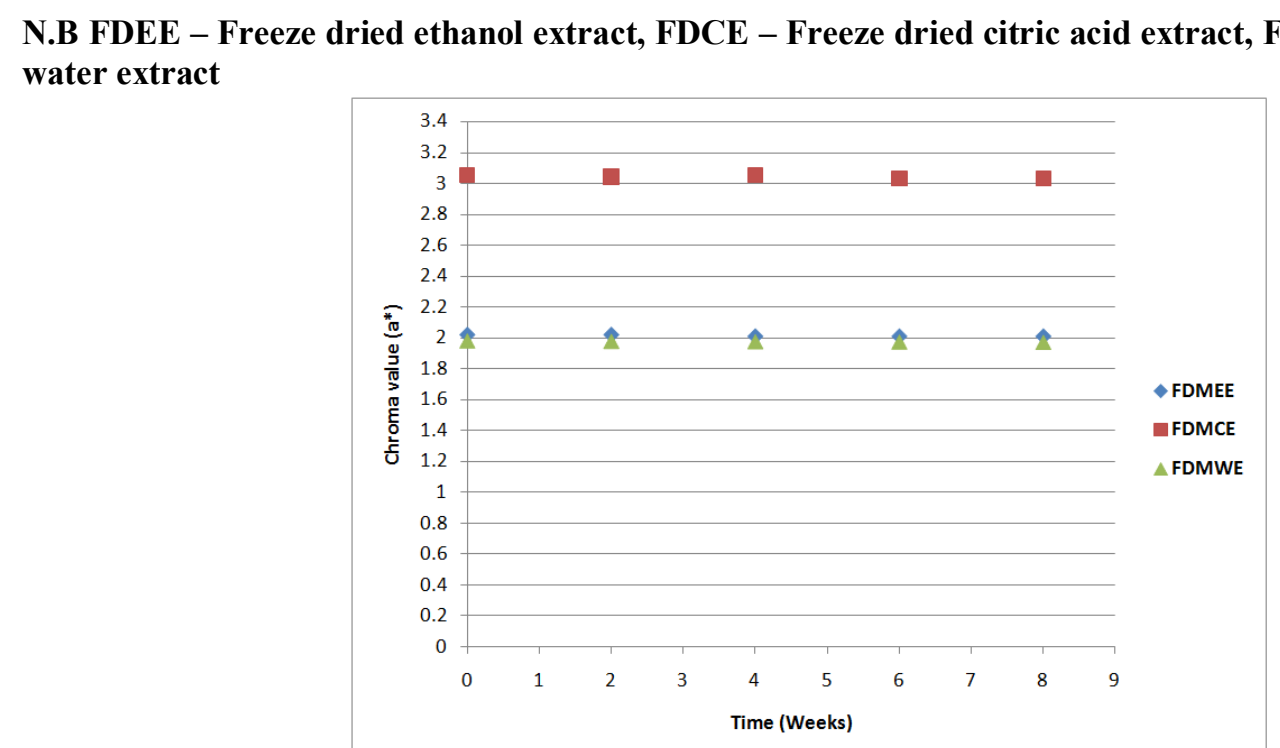

Figure 2: Changes in colour during storage of encapsulated extracts at $26^{\circ} \mathrm{C} \pm 2$ 
N.B FDMEE - Freeze dried microencapsulated ethanol extract, FDMCE - Freeze dried microencapsulated citric acid extract, FDMWE - Freeze dried microencapsulated water extract

3.3 Changes in $\mathrm{pH}$ of extracts with storage days

The $\mathrm{pH}$ variation of Freeze dried Roselle anthocyanins extracts is clearly depicted (Fig. 3). The results indicate that the FDCE and FDEE samplesexhibited more stability in $\mathrm{pH}$ (2.6 and 2.7 respectively)(days 1-16), but increasing slightly thereafter (days 16-22). The FDWE sample showed steady increase in $\mathrm{pH}$ (from $\mathrm{pH} 2.8$ ) only after day 7 . These could be attributed largely to the residual acidic effect of the extracting solvents. The effect of storage duration on the $\mathrm{pH}$ of the freeze dried extracts (FDWE) is evident in a steady rise in $\mathrm{pH}$ with storage days but not necessarily following in a straight line order. These observations are in agreement with those of Selim et al., (2008) who concluded that anthocyanins are stable only at low $\mathrm{pH}$.

The effect of storage days on the $\mathrm{pH}$ of the freeze dried microencapsulated extracts FDMWE, FDMEE, FDMCEindicates a rise in $\mathrm{pH}$ from initial storage period but variation pattern also did not follow a straight line order (Fig. 4). Changes in $\mathrm{pH}$ of the extracts may be due to some interaction between the starch matrix and the extract (including residual extracting solvent) especially when compared with their non-encapsulated ones (Fig. 3 ). These variations though evident did not however significantly impact on the colour intensity over the storage duration (Fig.2).

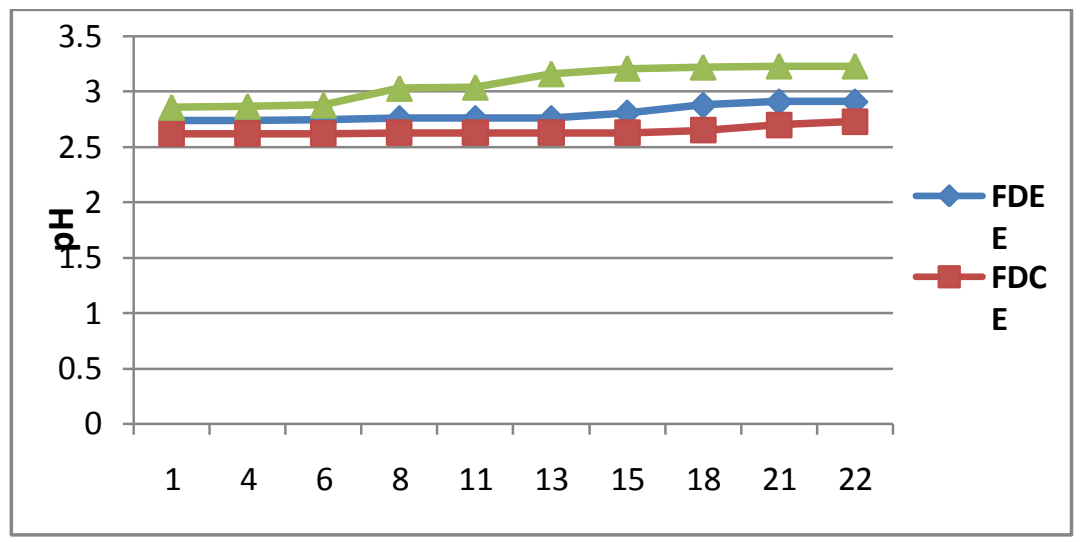

Time (Days)

Figure 3: Variation inpH of Freeze dried Roselle anthocyanins extracted with different solvents at $26^{0} \mathrm{C} \pm 2$ N.BFreeze dried ethanol extract (FDEE), Freeze dried citric acid extract (FDCE), Freeze dried water extract (FDWE).

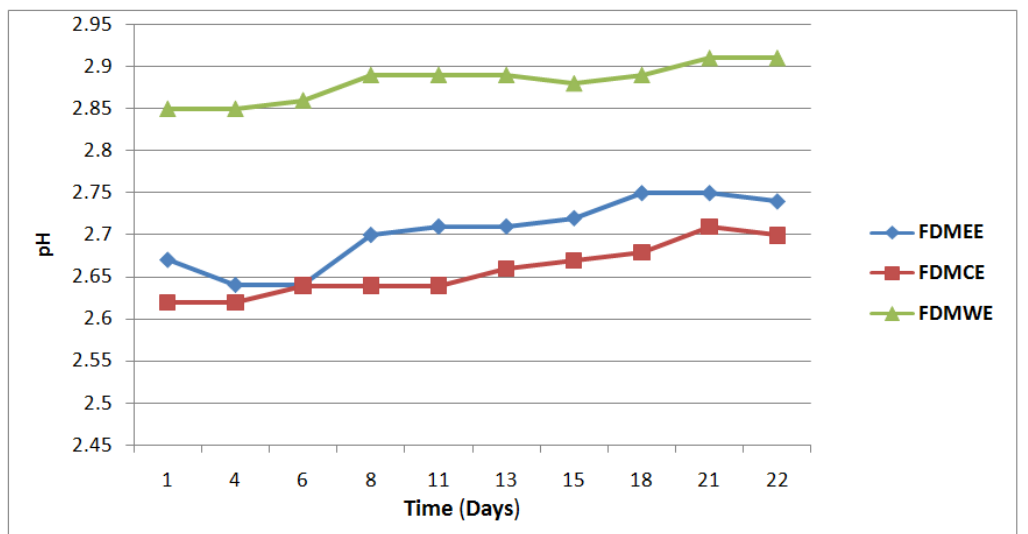

Figure 4: Variation in pH of Freeze dried Roselle Microencapsulated anthocyanins extracted with different solvents at $26^{\circ} \mathrm{C} \pm 2$

N.B Freeze dried microencapsulated ethanol extract (FDMEE), Freeze dried microencapsulated citric acid extract (FDMCE), Freeze dried microencapsulated water extract (FDMWE).

3.4 Variation in ascorbic acid content of freeze dried extracts with storage days

A cursory look reveals more stability in FDCE and FDEE ascorbic acid contents, when compared tothat of FDWE (Fig. 5). Anthocyanin decomposition is accelerated by the presence of ascorbic acid (Marti et al., 2002; Poei-Langston and Wrolstad, 1981).

Also the formation of hydrogen peroxide from ascorbic 
acid oxidation can influence anthocyanin stability (Markakis, 1982; Takcott et al., 2003). However the stability of acylatedanthocyanins has been reported to increase in the presence of ascorbic acid (Del Pozo-Ins fran et al., 2004). The precise chemical interplay between ascorbic acid and the anthocyanin in this study needs to be further explored especially in view of the colour stability with time.Anthocyanins are also considered to be protected by ascorbic acid against enzymatic degradation (Talcott et al., 2003).

The variation in ascorbic acid content in the microencapsulated pigments is depicted in Fig. 6. Results showed that the microencapsulated extracts were less stable in ascorbic content when compared to their nonencapsulated counterparts. This might be due to residual oxygen entrapped within corn starch matrix now in intimate contact with ascorbic acid-generally known to be unstable in oxygen.

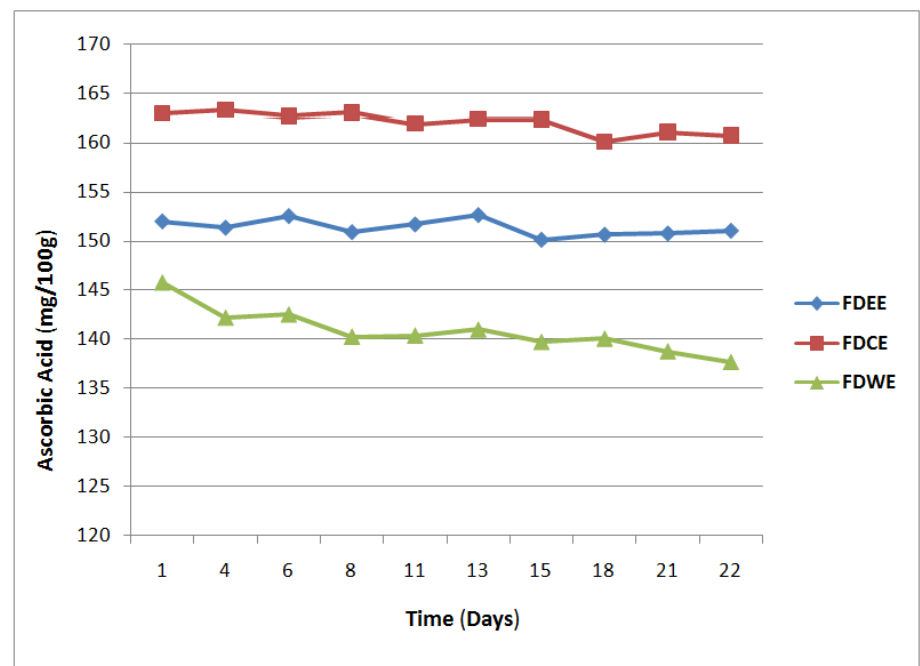

Figure 5: Variation in Ascorbic acid content of Freeze dried Roselle anthocyanins extracted with different solvents at $26^{\circ} \mathrm{C} \pm 2$

N.B Freeze dried ethanol extract (FDEE), Freeze dried citric acid extract (FDCE), Freeze dried water extract (FDWE)

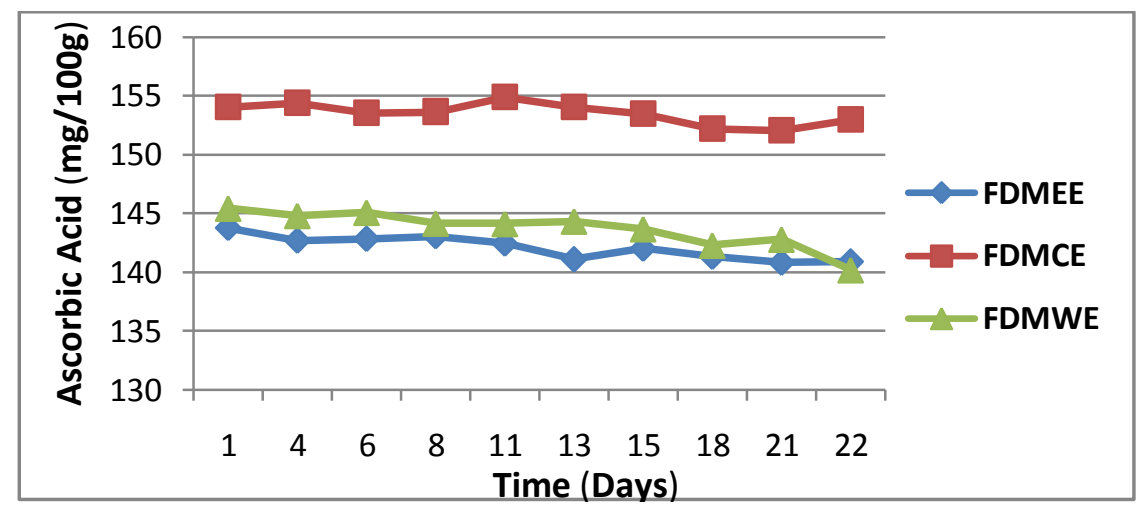

Figure 6: Variation in Ascorbic acid content of Freeze dried microencapsulated Roselle anthocyanins extracted with different solvents at $26^{\circ} \mathrm{C} \pm 2$.

\section{N.BFreeze dried microencapsulated ethanol extract (FDMEE), Freeze dried microencapsulated citric acid extract (FDMCE), Freeze dried microencapsulated water extract (FDMWE)}

\subsection{Changes in anthocyanins during storage}

A relative stability in anthocyanins content of the non-encapsulated pigments over twenty-two (22) days of storage is evident from Fig. 7. The total anthocyanins content of all the freeze dried extracts decreased during storage. The anthocyanins content of FDCE ranged from $1262.76 \mathrm{mg} / 100 \mathrm{~g}$ to $1258.17 \mathrm{mg} / 100 \mathrm{~g}$, followed by FDEE $(969.60 \mathrm{mg} / 100 \mathrm{~g}$ to $957.30 \mathrm{mg} / 100 \mathrm{~g})$ and FDWE the lowest $(887.43 \mathrm{mg} / 100 \mathrm{~g}$ to 880 $\mathrm{mg} / 100 \mathrm{~g})$. FDCE maintainedits high anthocyanins content with minimal loss $(0.34 \%)$ after days of storage. These slight losses inanthocyanins could be attributed to the fact that freeze drying is a viable option of protecting thermo sensitive and unstable molecules (Munin and Edwards - Levy, 2011). 
Variation in anthocyaninscontentof the microencapsulated samples with storage days are indicated in Fig. 8. The anthocyanins content of FDMEE ranged from $956.32 \mathrm{mg} / 100 \mathrm{~g}$ to $950.11 \mathrm{mg} / 100 \mathrm{~g}$, FDMCE (1218.13 to $1217.13 \mathrm{mg} / 100 \mathrm{~g}$ ), and FDMWE (877.16 mg/100g to $876.21 \mathrm{mg} / 100 \mathrm{~g})$. Although encapsulation decreased the effective concentration of anthocyaninsat the beginning of the study, their relative stability compared favourably with their non-encapsulated counterparts. The encapsulating agent did not appear to have significantly contributed to the stability of the anthocyanin content in the duration under review.

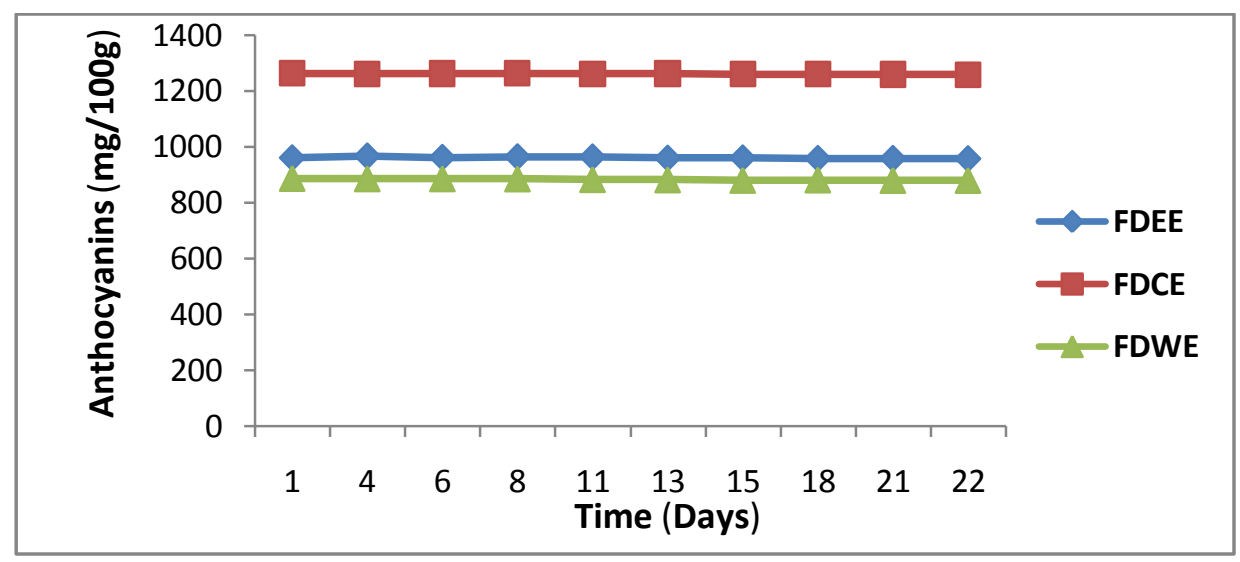

Figure 7: Variation inanthocyaninscontent of Freeze dried Roselle calyxes extracted with different solvents at $26^{\circ} \mathrm{C} \pm 2$

N.BFreeze dried ethanol extract (FDEE), Freeze dried citric acid extract (FDCE), Freeze dried water extract (FDWE)

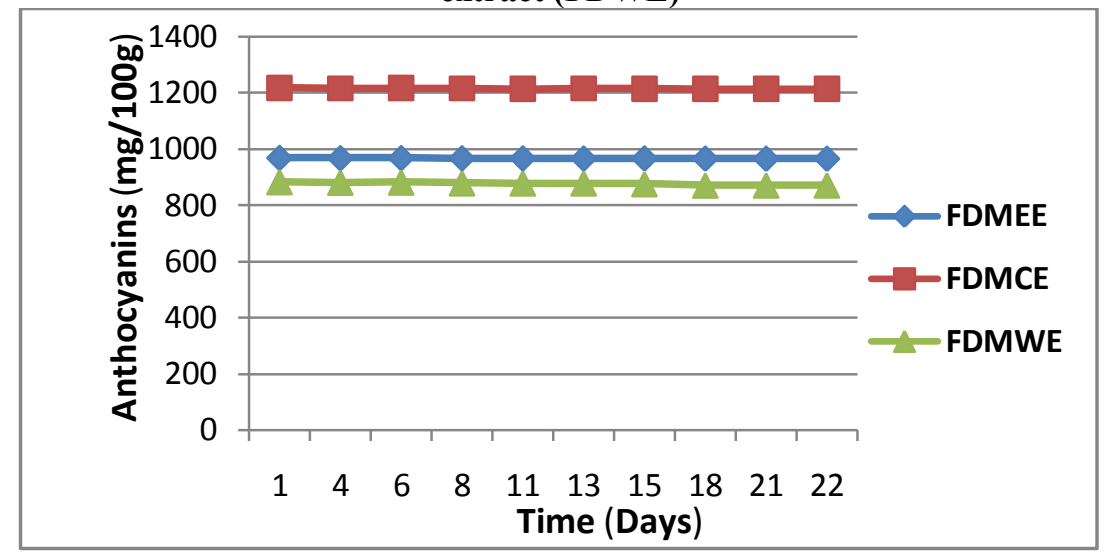

Figure 8: Variation inanthocyaninscontent of Freeze dried microencapsulated Roselle calyxes extracted with different solvents at $26^{0} \mathrm{C} \pm 2$

N.B: Freeze dried microencapsulated ethanol extract (FDMEE), Freeze dried microencapsulated citric acid extract (FDMCE), Freeze dried microencapsulated water extract (FDMWE)

3.6 Sensory evaluation of the jam samples

The results of sensory evaluation of the Water melon jams are presented in Table 2. Jams were prepared from Water melon pulp with different colourants. Four sample of jams were prepared at various composition-Jams B, C, D were fortified with synthetic, FDCE and FDMCE colour samples respectively at inclusion levels of $1 \%$. Jam A served as the control (without colourant).Generally, consumer responses were independent of the initial taste of Water melon jam. Overall, Jam B was most acceptable to panellists. Statistical analysis showed there was no significant difference in acceptability among different treatments at $p<0.05$. In terms of colour acceptability, Jam B gave highest mean score (7.6) although not significantly different from other Jams. As regards mouth feel the maximum mean score was Jam B (7.00), while Jam A(control) had the lowest mean score(6.83). The Jam B fortified with synthetic colourant was most acceptable (7.6) and indeed in most other sensory attributes but not significantly different from other Jams. Jam D gave the least mean score (6.93). The overall acceptability of Jam B (fortified with synthetic colourant) may be due to the high colour intensity it exhibited. The changes in sensory scores after two months of storage were not significantly differently from when freshly prepared. These observation compare favourably with those of Selim et al (2008). 
Stability Studies of Microencapsulated Anthocyanins of Roselle (Hibiscus Sabdariffa L) In Native

\begin{tabular}{|c|c|c|c|c|c|c|c|c|}
\hline \multirow{2}{*}{$\begin{array}{l}\text { Samples } \\
\text { Attributes }\end{array}$} & Jam A & Jam B & Jam C & Jam D & Jam A & Jam B & Jam C & Jam D \\
\hline & \multicolumn{4}{|c|}{ Freshly prepared } & \multicolumn{4}{|c|}{ After 2 months storage } \\
\hline Colour & $6.40 \pm 1.63^{b}$ & $7.60 \pm 1.22^{\mathrm{a}}$ & $7.03 \pm 1.29^{b}$ & $6.50 \pm 1.54^{b}$ & $6.10 \pm 1.21^{b}$ & $7.70 \pm 1.32^{\mathrm{a}}$ & $6.85 \pm 1.5^{b}$ & $\begin{array}{l}6.13 \pm 1.3 \\
7^{b}\end{array}$ \\
\hline Mouth feel & $4.46 \pm 3.36^{\mathrm{a}}$ & $4.46 \pm 3.46^{\mathrm{a}}$ & $4.30 \pm 3.39^{\mathrm{a}}$ & $4.50 \pm 3.53^{\mathrm{a}}$ & $4.0 \pm 3.21^{\mathrm{a}}$ & $4.50 \pm 3.11^{\mathrm{a}}$ & $4.53 \pm 3.12^{\mathrm{a}}$ & $\begin{array}{l}4.59 \pm 3.8 \\
1^{\mathrm{a}}-9\end{array}$ \\
\hline Texture & $6.83 \pm 1.44^{\mathrm{a}}$ & $7.00 \pm 1.33^{\mathrm{a}}$ & $6.93 \pm 1.63^{\mathrm{a}}$ & $7.00 \pm 1.55^{\mathrm{a}}$ & $6.21 \pm 1.4^{\mathrm{a}}$ & $7.12 \pm 1.30^{\mathrm{b}}$ & $5.97 \pm 1.73^{\mathrm{a}}$ & $\begin{array}{l}7.42 \pm 2.0 \\
1^{\mathrm{b}}\end{array}$ \\
\hline $\begin{array}{l}\text { Overall } \\
\text { acceptability }\end{array}$ & $6.69 \pm 1.49^{\mathrm{a}}$ & $7.60 \pm 0.93^{\mathrm{a}}$ & $7.06 \pm 1.48^{\mathrm{a}}$ & $6.93 \pm 1.28^{\mathrm{a}}$ & $6.52 \pm 1.15^{\mathrm{b}}$ & $7.53 \pm 1.0^{\mathrm{a}}$ & $6.84 \pm 1.60^{\mathrm{b}}$ & $\begin{array}{l}6.02 \pm 1.2 \\
5^{\mathrm{b}}\end{array}$ \\
\hline
\end{tabular}

N.B

Jam A = Control (no colourant), Jam B = Fortified with $1 \%$ synthetic colourant, Jam C = Fortified with $1 \%$ FDCE, Jam D = Fortified with $1 \%$ FDMCE.Sensory scores with higher value indicate greater preference while values with different superscripts in a row are significantly different $(\mathrm{P}<0.05)$

\section{Conclusion}

The physicochemical properties of the encapsulated and non-encapsulated extracts varied significantly particularly across samples. The chroma $\left(a^{*}\right)$ values of FDCE and FDMCE were higher than othersamples. The encapsulated pigments exhibited more stability with the passage of time. In some complex food system such as jams, puddings etc Roselle pigment encapsulated in corn starch holds great promise especially under room temperature storage conditions.

\section{References}

[1]. Abou-Arab, A.A., Abu-Salem, F.M. and Abou-Arab, E.A. Physico-chemical properties of natural pigments (anthocyanin) extracted from Roselle calyces (Hibiscus subdariffa). Journal of American Science. 7(7) 2011, 445-456

[2]. Adenipeku, I.T. Extraction and colours of Roselle (Hibiscus sabdariffa) juice. Ibadan, Nigeria: University of Ibadan, M.Sc. Thesis, 1978 .

[3]. Andersen, O.M. and Francis, G.W. Techniques of pigment identification. Annual plant reviews-Plant pigments and their manipulation, 14, 2004: 293-341.

[4]. AOAC. Official methods of analysis of AOAC, (14 ${ }^{\text {th }}$ Ed.) Association of analytical Chemist Washington D.C. 2000

[5]. Bridle, P and Timberlake, C.F. Anthocyanins as natural food colours - Selected aspects. Food Chemistry 58 (12) 1997, $103-109$

[6]. Builders, P.F., Chukwuemeka, R., Ezeobil, A., Florence, D., Tarfa and Builders, M.I. Assessement of the intrinsic and stability properties of the freeze-dried and formulated extract of Hibiscus sabdariffa Linn. (Malvaceae). Africal Journal of Pharmacy and Pharmacology, 4(6) 2010, 304-313.

[7]. Chumsri P., Sirichote, A. and Itharat, A. Studies on the optimum conditions for the extraction and concentration of roselle (Hibiscus sabdariffa Linn) extract. Songklanakarin J. Sci. and Technol. 30(Suppl. 1) 2008, 133-139

[8]. Clydesdale, F.M., Main, J.H., Francis, F.J. Roselle (Hibiscus sabdariffa L) anthocyanins as food colourants for beverages and gelatine desserts. Journal of food protection, 42, 1997, 204-207.

[9]. Del Pozo-insfran D., Brenes C.H. and Talcott S.T. Phytochemical composition and pigment stability of Acai (Euterpeoleracea Mart.). Journal of Agricultural and Food Chemistry. 52, 2004, 1539-1545.

[10]. Du C. T., and Francis F .J. Anthocyanins of roselle (Hibiscus sabdariffaL.) Journal of Food Science. 38, $1973,818$.

[11]. Esselen, W.B, and Sammy, G.M. Roselle-a natural red colourant for foods? Food product development, 7(2), 1973, 80-82, 86

[12]. Esselen, W.B. and Sammy, G.M. Application ofroselle as a red food colourant. Food product Development, 9(10), 1975, 37-38, 40.

[13]. FAO. Guidelines for small-scale fruit and vegetable processors (FAO Agricutural services bulletin - 127), 1997 Downloaded from http://www.fao.org/docrep/w6864e/w6864e00.HTM on 13th August 2012

[14]. Flink, D.D. Safety of polyphenolic compounds. World Science Journal, 4(5), 1985, 845-849.

[15]. Ghorpade, V.M, Deshpande, S.S and Salunkhe, D.R. Food colours. In Maga, J. And Anthony T. (Eds) Food additive toxicology, p. 179-233. New York: Marcel Dekker,1995.

[16]. Giusti, M.M. and Wrolstad, R.E .Acylatedanthocyanins from edible sources and their applications in food system. Biochemical Engineering Journal 14 (3), 2003, 217-225.

[17]. Gradinaru, G; Biliaderis, C.G., Kallithraka, S., Kefalas, P. and Garcia-Veguera, C. Thermal stability of Hibiscus sabdariffa L. Anthocyanins in solution and in solid state effects of copigmentation and glass transition. Food Chemistry, 83, 2003, $423-436$.

[18]. Hendry, G.A.F and Houghton, J.D. Natural Food Colourants. In Hendry G.A.F and J.D. Houghton (Ed). Natural pigments in Biology: Definitions, p 59-64. London: Blackie and Professional, 1995.

[19]. Leahy, M. M., Anandaraman, S., Bangs W. E., and Reineccius, G. A. A comparison of encapsulating agents for the drying of artificial flavours. Perfumer Flavorist, 8, 1983, 49-57.

[20]. Leung, H.K. Influence of water activity on chemical reactivity. In Rockland L.B and Beuchat L.R (Eds). Water theory and applications in food, p 27-54. New York Marcel Dekker.1987.

[21]. Markakis, P. Stability of Anthocyanins in food. In Markakis P. (Ed). Anthocyanins as food colours. p 163-178. New York: Academic Press Inc.1982

[22]. Marti, N., Perez-Vicente A., and Garcia-Viguera, C. Influence of storage temperature and ascorbic acid addition on pomegranate juice. Journal of the Science of Food and Agriculture, 82, 2002, 217-221

[23]. Mattuk, H.I. Studies on the utilization of natural pigments extracted from some plant sources. Egypt J. Appl. Sci., 13, 1998, 286303

[24]. MuninAude and Florence Edwards-Lévy. Encapsulation of Natural polyphenolic compounds, a review. Pharmaceutics, 3, 2011, 793-829 
[25]. Parize, A.L., Rozone de Souza T. and Brighente, I.M.C., De Faverel V.T., Laranjeira M.C.M.,Spinelli, A. and Longo, E. Microencapsulation of the natural urucum pigment with chitosan by spray drying in different solvents. African Journal of Biotechnology, 7(17), 2008, 3107-3114.

[26]. Poei-Langston, M. S. and Wrolstad, R. E., Colour degradation in an ascorbic acid-anthocyanin-flavanol model system. Journal of Food Science 46, 1981, 1218, 1222, 1236.

[27]. Pouget, M.P, Legeune, B., Vennat B. and Pourrat, A. Extraction, analysis and study of the stability of Hibiscus anthocyanins. Lebensmittel-Wiissenschaft and Technologie, 23, 1990,103-105.

[28]. Rein, M.J. Copigmentation reactions and colour stability of berry anthocyanins (dissertation). EKT series 1331. Finland: University of Helsinki, Academic dissertation ,2005. Downloaded from http://ethesis.helsinki.fi/julkaisat/maa/skemi/vk/rein/copigmen.pdf on 20th June 2012.

[29]. Sandhu, K.S. and Singh, N. Some properties of corn starches II: Physicochemical, gelatinization, retrogradation, pasting and gel textural properties. Food Chemistry 101, 2007, 1499-1507.

[30]. Selim K. A., Khali K. E., Abdel-Bary M. S., and Abdel-Azeim, N. A .Extraction, Encapsulation and Utilization of Red Pigmentsfrom Roselle (Hibiscus sabdariffaL.) as Natural Food Colourants. Alex Journal of Food Science and Technology. Special volume conference pp 7-20, 2008. Downloaded from http://www.fayoum.edu.eg/agriculture/foodsciences/pdf/drkhaled01.pdf on 15 th June 2012 .

[31]. Stanciu, G., Lupsor, S., Sava, C. and Zagan, S. Spectrophotometric study on stability of anthocyanins extracts from black grapes skins. Ovidius University Annals of Chemistry 21(1),2010, 101-104.

[32]. Talcott, S.T., Brenes C.H., Pires D.M. and Del Poto-Insfran D. Phytochemical stability and colour retention of copigmented and processed muscadine grape juice. Journal of Agricultural and Food Chemistry. 51, 2003, 957-963.

[33]. Tsai, P.J. and Huang, H.P. Effect of polymerization on the antioxidant capacity of anthocyanins in roselle. Food Res. Int. 37, 2004, 313-318.

[34]. Wolf, B.W, Garleb, K.A., Choe, Y.S., Humphrey, P.M. and Maki, K.C.Pullulan is a slowly digested carbohydrate in humans. J. Nutrition, 133(4), 2003, 1051-5. 